\title{
Examination of decision-making skill in the context of critical situations
}

\author{
Fatma Nur Aktaş ${ }^{1 *}$, Esra Selcen Yakıc1-Topbaş ${ }^{1}$, and Yüksel Dede ${ }^{1}$ \\ ${ }^{1}$ Gazi University, Faculty of Education, Departmen of Mathematics Education, Ankara, Turkey
}

\begin{abstract}
A teacher, who has a major role in the formation of class culture, needs to have proficiencies to design effective learning environments. The reflection of these proficiencies on classroom practices takes place via the decisions taken under critical situations. This study aims to find out the components underlying teachers' decision-making. Participants of the study which was designed as a case study were elementary school mathematics teachers. The study was carried out through the individual interviews with participants about the decision making under critical situations after analysing participant teachers' course observations which were video-recorded by the researchers. Data obtained from the interviews were analysed through content-analysis method. Based on the findings, it was found that teachers' professional proficiencies could be presented in the same frame with the variables reflected on decision making.
\end{abstract}

\section{Introduction}

Teacher proficiencies are important in designing effective learning environments in the class in which many dependent or independent conditions occur at the same time. In these critical situations, the teacher who has one of the most important roles in the class is notable for his decision making. When we examine the conceptual framework of the components that influence the decision-making process, which can be defined as the sum of the physical and cognitive efforts in the selection and preference of various conditions, it is seen that the variables affecting this process are quite diverse: teaching situations, goals, learning outcomes, experience, awareness, beliefs and values. Students, expressions of the students and their thinking are important elements that should be taken into consideration in classroom practices by the teacher who is an actor in the class. These elements, in which teachers display their skills and proficiencies are crucial situations necessitate important decision making. Therefore, it is important to identify the elements underlying the decisionmaking mechanisms of the teachers to whom we cast a significant role in designing effective learning environments or the variables reflected on this process.

Classroom environment as the complex structure of historical, social and cultural influences, which are classroom discussions, small group works, problem solving activities, researches and skills of carrying out similar activites of a teacher are limited as explicit or

* Corresponding author: fnuraktas@gmail.com 
implicit by classroom atmosphere, [5]. All variables occurring during the classroom practices such as socio-cultural interactions affected as socially or personally, grade, gender, ethniticity, teacher-student interactions influence classroom culture. In mathematics as a discipline among those variables reflecting on classroom practices, it is possible to mention about the affective factors of teachers together with the cognitive factors $[2,6]$. McClain [8] exemplifies the classroom practices and mathematical ideas in mathematics class with activities such as reasoning, discussing and symbolising. In mathematics teaching process, it is possible to mention about classroom practices such as placing different problem solving strategies and discussions, having students work in groups, selecting problem solving method.

The skills that teachers need to own to make decisions so as to respond to the growing needs of their students also increase. Partnership21 (2015) categorized the learner skills as shown in Table 1 . Those skills take place as lifesaving skills in $21^{\text {st }}$ century in literature.

Table $1.21^{\text {st }}$ century skills

\begin{tabular}{|c|c|c|}
\hline $\begin{array}{c}\text { Learning and innovation } \\
\text { skills }\end{array}$ & Life and career skills & $\begin{array}{c}\text { Information, media and } \\
\text { technology skills }\end{array}$ \\
\hline $\begin{array}{c}\text { critical thinking and problem } \\
\text { solving }\end{array}$ & flexibility \& adaptability & information literacy \\
\hline creativity and innovation & Initiative \& self-direction & media literacy \\
\hline $\begin{array}{c}\text { communication and } \\
\text { collaboration }\end{array}$ & social \& cross-cultural skills & $\begin{array}{c}\text { ICT (information, communications } \\
\& \text { technology) literacy }\end{array}$ \\
\hline & leadership \& responsibility & \\
\hline
\end{tabular}

These skills have importance in terms of teachers' both individual and professional development as educators in addition to being a requisite by the students. When teacher professional proficiencies which were revised by Ministry of National Education are taken into consideration, it is seen that professional knowledge (pedagogical content knowledge, knowledge of legislation) and skills (educational planning, creating learning environments, management of teaching and learning, assessment and evaluation) are associated with attitude and values as in Table 2 below to $21^{\text {st }}$ century skills.

Table 2. Teacher proficiencies and $21^{\text {st }}$ century skills

\begin{tabular}{|c|c|}
\hline $\mathbf{2 1}^{\text {st }}$ century skills & Teacher proficiencies \\
\hline creativity & educational planning \\
\hline \multirow{2}{*}{ critical thinking } & educational planning \\
\cline { 2 - 2 } & management of teaching and learning process \\
\cline { 2 - 2 } communication \& collaboration & measurement and evaluation \\
\cline { 2 - 2 } & educational planning \\
\cline { 2 - 2 } & creating learning and teaching environments \\
\hline information, media and technology & management of teaching and learning process \\
\cline { 2 - 2 } literacy & knowledge of legislation \\
\hline \multirow{3}{*}{ flexibility \& adaptability } & knwoledge of pedagogy \\
\cline { 2 - 2 } & creating learning and teaching environments \\
\cline { 2 - 2 } social \& cross cultural skills & educational planning \\
\cline { 2 - 2 } & management of teaching and learning process \\
\cline { 2 - 2 } & educational planning \\
\hline
\end{tabular}

Based on this view, it can be said that the educational requirements of modern days, the new meanings of education and teaching attributed to teachers, the differentiating needs of the students, new approaches on the education of the individuals lay new responsibilities on the teachers regarding their professional dimension. In this context, teaching is regarded as a profession that requires high qualifications that can completely bear the responsibility of 
human life. It is inevitable to say that when the reflection of such skills and proficiencies on classroom practices is examined, the teacher plays the decision-making mechanism role in role in the classroom. Decision-making as a skill and decision-making process need to be evaluated and explained as teacher-centered in the context of classroom practice.

\subsection{Teacher and Decision Making}

The teacher, like an actor, plays a role for which $\mathrm{s} / \mathrm{he}$ is expected to make and maintain the necessary arrangements according to the content of the subject. This role of the teacher is to organize the learning environment according to the objectives of the teaching. The situations that the teacher should make a decision can be taken in a broad perspective as all critical situations of classroom practice, culture and interaction.

The Turkish Language Association [16] defines "decision-making" compound word as "finalizing a problem to a decision, determining". However, Kuzgun [7] takes the decision making as a behaviour when there are more than two ways taking to an object, a person, a situation etc. thought to meet the need, or to determine whether these are adequate to satisfy the need intended to reach. In the widest sense, it is the sum of physical and mental efforts related to making a choice and a preference among various situations, [15].

Teachers often have to make decisions in teaching environments to design, implement, maintain, complete, and evaluate classroom practices, and to determine about the probable situations or problems in these processes. Because of this reason, decision making is one of the most fundamental aspects of the teaching process, and the more information about how the teachers make decisions is obtained, the more prediction about how to make their teaching can be done [1]. Thus, it is important that mathematics teachers have the ability to make decisions besides the mathematical knowledge necessary for teaching mathematics in order to enhance mathematical thinking of the students and maintaining this capability. Therefore, decision-making skill is a skill including the pre-inclass interaction, in the moment-course of interaction and post-class interaction. Teacher decisions are not only about inclass behaviors, but they also involve the beginning and the end of the classes.

Simon deals with decision-making process in three basic stages:

- gathering information: identifying situations that need to be decided;

- planning: finding possible styles of action and

- making choice: a choice among the styles of action, [14].

By following these steps and passing through the decision-making filter, the teacher's decisions emerge in classroom practices, and this process is called the teacher's strategy by [1]. Bishop and Whitfield [3] demonstrate the teacher's decision-making filters and interpretations of decision making in the frame of Figure 1.

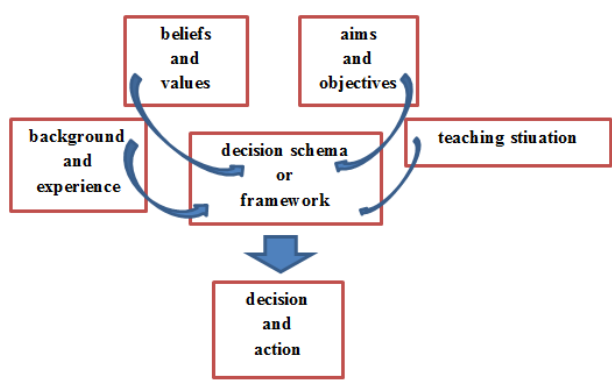

Fig. 1. Bishop and Whitfield, the framework of teacher' decision-making ([3], p.6) 
Munby [11], on the other hand, dealt with teacher decisions based on student thinking in the context of teacher decision-making. Here, situations that need to be decided rather than the decision of the teacher is focused. For example, he provided a broad framework covering outputs such as pre-requisites (student information, school environment etc.), personality of teacher (belief etc.), cognitive processes (such as information and goals), planning of teaching and interaction with the student. In other words, Munby [11] presented an overview of the teacher's thinking, decision-making and practice field. As can be seen, there are researches revealing and examining the decision-making ability as well as the variables reflected in the teacher's decision-making process.

In this research, it is aimed to examine and determine the situation of the critical situations in which teacher has to make decision and that occur in the classroom environment, the variables influencing these critical situations and what the decisions taken are. Thus, it will be possible to obtain a broad perspective on teacher decision-making processes. The emphasis on the importance of decision making skill under all possible components when examining teacher proficiencies and indicators of those proficiencies. At the end of our research, it is aimed to establish a framework for effective decision making as a teacher proficiency.

\section{Method}

The participants of this research, which was designed in a multiple-case study design of the qualitative research designs, were three mathematics teachers with differentiating seniority (years). Participants determined based on volunteer basis with easily accessible sampling of purposeful sampling methods work in two state secondary schools located at the same socioeconomic level. In the literature, it is emphasized that in elementary school classrooms, there are a lot of student-student and student-teacher interaction and that the situations in which the teacher needs to pay much more attention and make decision how to behave is often encountered in comparison to the level of secondary school education $[4,12,13]$. For this reason, teachers instructing 7 th grade mathematics courses that include outcomes of algebraic, analytical, and geometric thinking coexisted, and thus providing opportunities for different student thinking, were included in the research.

Westerman [17] identified significant differences between the decision-making processes of a expert and novice teacher. One of the most notable of them was an experienced teacher gave feedback by taking student needs into consideration while novice teacher ignored those variables or didn't take into account. Considering this framework, participants were chosen by varying in their seniority years, as shown in Table 3.

Table 3. Participant information

\begin{tabular}{|c|c|c|c|}
\hline Teacher & Gender & Seniority (year) & Graduated faculty \\
\hline T1 & female & 1 & $\begin{array}{c}\text { department of secondary school mathematics } \\
\text { teaching }\end{array}$ \\
\hline T2 & male & 14 & $\begin{array}{c}\text { department of elementary \& secondary school } \\
\text { mathematics teaching }\end{array}$ \\
\hline T3 & male & 41 & institute of mathematics education \\
\hline
\end{tabular}

Data collection instruments were video recordings taken during classes (4 hours of consecutive lesson), observation notes and semi-structured individual interviews during instruction.

Firstly, the lessons designed by teachers for the outcomes (polygons and transformation geometry) in different sub-learning areas were recorded in video recording. In the video recordings analyzed by the researchers, situations where participants make decisions or 
require decision making. These specific phenomena were defined as critical situations in our study. In other words, these critical situations in our research were the phenomena that we observed based on specific situations, such as giving a right to speak, feedback, comprehension, or focus on the student, either directly or through a teacher interview. In individual interviews, the critical situations determined for each participant's own lectures were inquired by the participant. The interview sessions lasted about 6 hours in total with each teacher in 3 sessions. The findings obtained from these interviews and the variables reflecting the decision-making process in critical situations were identified. Through the individual interviews, the variables identified by the researchers were both confirmed by the teachers and underlying variables of the decisions were determined. The obtained data were analyzed by content analysis, [9]. The analysis unit of the study were the variables underlying decision making with teacher opinions based on the critical situation and their decision making. Indicators of critical situations and the components underlying decision making were identified by researchers in consensus, [10].

\section{Findings and Conclusion}

The findings of the teachers' decision-making processes about critical situations, the reasons for the decisions and the variables influencing the decision making and the findings from the course records were presented to describe the analysis process in order to facilitate the interpretation of the results.

A part of $\mathrm{T} 2$ from the praticipants for reviewing with the students of the previous lesson is given:

T2: What is polygon? Who will explain it to us?

Only three students raise their fingers. The teacher does not wait the other students to raise their fingers.

T2: Friends! Listen, then we'll go on. Görkem ${ }^{\dagger}$, can you explain?

Görkem: The shape that has at least three sides and a corner.

T2: Yes. [...]

The critical situation here is why T2 didn't wait for the others and why he gave the right to speak to Görkem. The reason why T2 chooses Görkem can be indicated as the factor influencing his decision-making process. When T2 had the classroom application watched in the interview, he explained his reasons to make this decision with the following statements.

T2: Görkem is a passive student. But, she is successful and also smart. When I ask her a question or want her to summarize, she both feels self-confident and I take her attention to the class. Görkem is a kid requiring attention. I want every student speak and be active in the class. Sometimes, I try to encourage them to participate in discussions as well.

Here there are two notable reasons of T2's decision making. While, at first, the reason for choosing Görkem openly is to take the student's self-confidence and motivation into account, the emphasis on the importance given to the freedom of expression of students takes place implicitly.

It is observed that the variables influencing the decision making skill of $\mathrm{T} 3$ in a noticeable situation in the video recording of the lesson are to provide active participation

\footnotetext{
${ }^{\dagger}$ Student names used in this chapter are all nicknames
} 
of the students in the class and to give equality of opportunity to the students at different levels.

T3 divides the board into four and have students write different questions at the same time.

When T3's opinion on this situation was taken about this situation, he presented the following explanation.

T3: There is a student who is very fast, that is, the student who makes the question very quickly, I divide the board in order to give time for them to do other questions. [...]

Class culture, the relationship between student and teacher, and school culture are important variables playing role on teacher decisions and classroom practices. One of our participants, T1, is an inclusive class teacher. The interaction of the inclusive student and inclusive student with teacher and other students creates critical situations for the teacher decision-making process. Below, it is seen that the variables reflected in T1's decision to classroom practices are found implicitly in the interviews, even if not in the course videorecords.

T1 draws various polygons with the help of GeoGebra. Ekrem (inclusive student) starts to laugh. T1 turns and looks at Ekrem. While T1 was explaining the examples, Ekrem brings his notebook and shows it to his teacher.

T1: Good. Do you want to wash your face?

Ekrem goes out of class.

Ekrem: You've kicked me out of it, have not you? (Crying)

T1: No, I've asked you to wash your face.

Ekrem closes the door. T1 continues to explain the examples. T1 finishes explaining the problem. Then, T1 opens the door and has look at Ekrem. Ekrem and the training coach have been waiting in front of the door.

T1: I wanted him to wash his face.

Ekrem and the training coach go to the lavatory. T1 goes on his class.

In this video recording of the course, that $\mathrm{T} 1$ asked Ekrem a question, the question she asked, her focusing preliminary on the problem which she was explaining, and then, opening the door and controlling Ekrem all generate critical situations. Out of those critical situations, T1's focusing on classroom practice and then decision of paying attention to Ekrem emerged in the interview.

T1: The training coach will ask me whether I kicked him out of the class or not. He is asking me if I have taken him out of class. Training coach is always interested in Ekrem. This is very good for us. Because, someone constantly has to take care of him.

Thus, it can be said that $\mathrm{T} 1$ has a priority order of the variables focused depending on the situation. Here, training coach is a variable influencing the order of the situatons of the teacher.

It is possible to interpret the results in the light of the findings and to categorize the variables that influencing teacher decision making processes. The most notable result of our research is that the teacher's decisions change depending on the situation. The teacher needs to be interested in many situations at the same time and to decide to respond (or ignore) to these situations. Therefore, it is necessary to put these critical situations in order of priority and to choose important ones. 
In this case, there are variables reflected on the teacher's decision. In Figure 2, there are categories from the findings of the decision making of the teachers.

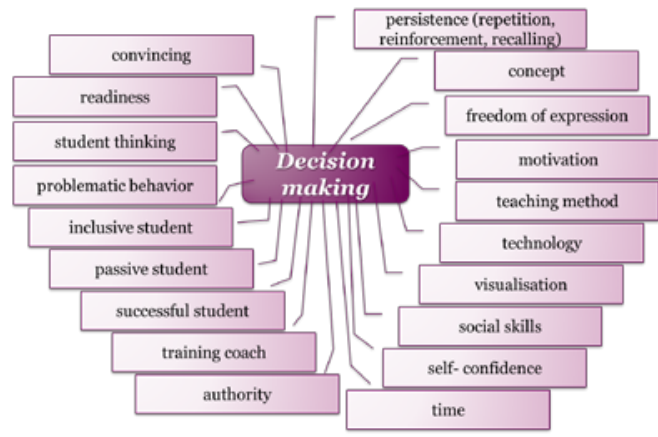

Fig. 2. Variables reflecting on decision making

When the obtained categories were analysed, it is possible to sum all under themes such as student knowledge (student thinking, readiness, passive-active student, inclusive student etc), content knowledge and pedagogical content knowledge (concept and teaching methods etc) creating learning environment (visualisation and freedom of expression etc), planning of education and training as teacher proficiencies. We can say that decision making skill reflects on each dimension of teacher proficiency. In other words, it is a significant result to deal decision-making skills within teacher proficiencies. It is therefore important to develop decision-making skills to train qualified teachers and to develop them as professional teachers. Thus, it may be recommended that the ability to make decision as a teacher professional proficiency is to be included in the literature.

The study finding out the result that novice teachers unlike from the experienced ones teach by not taking the needs of student needs into account differs from the inexperienced teacher of this current study [17]. This complies with the result setting forth that there are many factors playing role on the teacher's decision making. That is to say, interpretation of the decision making skill is not sufficient enough based on only seniority year and experience. With this result, many teacher proficiencies are emphasized together.

This research on critical situations reveals that the teacher's decision making skill can take form based on the specific situation as well as the reflection of the related variables. In short, as the decisions taken may change, underlying reason of the decision may also change. Thus, we can say that decision making is a changing skill depending on the situation. Based on this conclusion, organizing situation-specific activites to have teachers and pre-service teachers gain and develop decision making skill and analysing the videos of their own courses or different course videos having critical situations can be recommended as a proposal for teacher training and in-service teacher training.

It was found that while some of the decisions of teachers in various situations within the classroom environment were clearly observed, in some cases their decisions were implicit. This is why it is useful to support this process of identifying, reasoning or developing decision-making skills with observations of behaviors involving classroom interactions, as well as interviews reinforced by participant confirmation. Additionally, a comprehensive investigation of the variables underlying teacher decision-making skills with teachers with long-term and different qualifications (seniority, school level, class level, etc.) can be presented as a proposal for further studies.

This paper was presented as an oral presentation at ERPA International Congresses on Education 2018 congress. 


\section{References}

1. Bishop, A. J., Teacher Decision Making. Critical Issues in Mathematics Education (Edt.Clarkson, P., Presmeg, N.), Springer, (2008).

2. Bishop, A. J., FitzSimons, G., Seah, W. T. \& Clarkson, P., Values in mathematics education: Making values teaching explicit in the mahematics classroom. Paper presented at the combined Annual Meeting of the Australian Association for Research in Education and the New Zealand Association for Research in Education. Melbourne, Australia, (1999, November).

3. Bishop, A. J., \& Whitfield, R. C., Situations in teaching. McGraw-Hill, (1972).

4. Chapman, O. (2017). Understanding elementary school teachers of mathematics. Journal of Mathematics Teacher Education, 20(3), 203-205.

5. FitzSimons, G., Seah, W., Bishop, A.J. \& Clarkson, P. (2000). Conceptions of values and mathematics education held by Australian primary teachers: Preliminary findings from VAMP. Proceedings of the History and Pedagogy of Mathematics Conference, National Taiwan Normal University, Taipei. http :// www. education. monash. edu. au/ projects / vamp / hpm2000c. pdf (November 2012).

6. Handal, B., Teachers' mathematical beliefs: A review. The Mathematics Educator, 13(2), 47-57, (2003).

7. Kuzgun, Y., Meslek Gelişimi ve Danışmanlığı (2. Baskı). Ankara: Nobel Yayın Dağıtım, (2006).

8. McClain, K., A methodology of classroom teaching experiments. Researching Mathematics Classrooms: A Critical Examination of Methodology. Edt: Googchild, S. ve English, L. USA: Information Age Publishing, (2005).

9. Merriam, S. B., Qualitative Research: Designing, Implementing, and Publishing a Study. In Handbook of Research on Scholarly Publishing and Research Methods (pp. 125140). IGI Global, (2015).

10. Miles, M. B., Huberman, A. M., Huberman, M. A., \& Huberman, M., Qualitative data analysis: An expanded sourcebook. sage. (1994).

11. Munby, H., The place of teachers' beliefs in research on teacher thinking and decision making, and an alternative methodology. Instructional science, 11(3), 201-225, (1982).

12. Öztürk, B., Sınıf içi etkileşim. Kuram ve Uygulamada Egitim Yönetimi Dergisi, 6(4), pp. 621-640, (2000).

13. Rowland, T., Huckstep, P., \& Thwaites, A., Elementary teachers' mathematics subject knowledge: The knowledge quartet and the case of Naomi. Journal of Mathematics Teacher Education, 8, 255-281, (2005).

14. Simon, H. A., Yönetimde yeni karar verme bilimi, Amme İdare Dergisi, 7(3). Translate: Mustafa Tosun, (1970).

15. Taşç1, Ö., İlköğretim Öğretmenlerinin Okul Yöneticilerinin Karar Verme Sürecindeki Etkilerine İlişkin Algıları İle Örgütsel Adanmışlıkları Arasındaki İlişki. Master Thesis, Yeditepe University, Institute of Social Science, İstanbul, (2011).

16. Türk Dil Kurumu [TDK]. Türkçe sözlük (9. bs). Ankara, (1998).

17. Westerman, D. A., Expert and novice teacher decision making. Journal of teacher education, 42(4), 292-305, (1991). 